\title{
OS SENTIDOS DO TRABALHO
}

\author{
Estelle M. Morin \\ Psicóloga e Professora Titular da HEC - Ecole des Hautes Etudes Commerciales. \\ E-mail: estelle.morin@hec.ca \\ Tradução: Angelo Soares, Professor de Comportamento \\ Organizacional da Université du Québec à Montréal (UQAM).
}

\begin{abstract}
RESUMO
O trabalho representa um valor importante nas sociedades ocidentais contemporâneas, exercendo uma

influência considerável sobre a motivação dos trabalhadores, assim como sobre sua satisfação e sua produtividade. Compreender os sentidos do trabalho hoje é um desafio importante para os administradores, tendo em vista as múltiplas transformações que têm atingido as organizações e os "mundos do trabalho". O objetivo deste artigo é determinar, identificar e comentar as características que o trabalho deveria apresentar a

fim de ter um sentido para aqueles que o realizam. Acreditamos que os momentos de transformação organizacional constituem, potencialmente, uma oportunidade para reorganizar o trabalho de tal forma que a qualidade de vida e a eficácia organizacional sejam melhoradas e que as características que se atribuem a um trabalho que tem um sentido possam orientar as decisões e as intervenções dos responsáveis pelos processos de transformação organizacional.
\end{abstract}

\begin{abstract}
Work represents an important value in contemporary western societies, and exerts a considerable influence on workers' motivation, as well as on their satisfaction and productivity. Understanding the meanings of work represents an important challenge for managers, considering the many and multiple transformations that organizations and the "worlds of work" have been going on. The main objective of this article is to establish, to identify and to comment the main characteristics that work should have in order to be meaningful for those who accomplish it. In these moments of organizational transformations, there are many potential and important opportunities to reorganize the work organization. To improve the quality of life and the organizational effectiveness, it is important that the characteristics related to meaningful work may guide the decisions of those who are responsible for the processes of organizational transformations.
\end{abstract}

ABSTRACT

PALAVRAS-CHAVE

Trabalho, sentidos do trabalho, organização do trabalho, comprometimento no trabalho, mudança organizacional.

KEY WORDS

Work, meanings of work, organization of work, commitment at work, organizational change. 


\section{INTRODUÇÃO}

Assistimos hoje a transformações importantes no mundo do trabalho. Novas formas de organização aparecem, e a natureza se modifica. Observamos o desaparecimento de empregos permanentes e, simultaneamente, aparecem novas tecnologias e formas inovadoras de organização do trabalho. Ao mesmo tempo em que milhares de pessoas sofrem pela falta de uma vaga, outras sofrem pelo fato de terem que trabalhar excessivamente.

O trabalho conserva um lugar importante na sociedade. Para a pergunta: "se você tivesse bastante dinheiro para viver o resto da sua vida confortavelmente sem trabalhar, o que você faria com relação ao seu trabalho?", mais de $80 \%$ das pessoas pesquisadas respondem que trabalhariam mesmo assim (Morin, 1997; Morse e Weiss, 1955; Tausky, 1969; Kaplan e Tausky, 1974; MOW, 1987; Vecchio, 1990). As principais razões são as seguintes: para se relacionar com outras pessoas, para ter o sentimento de vinculação, para ter algo que fazer, para evitar o tédio e para se ter um objetivo na vida.

$\mathrm{O}$ trabalho representa um valor importante, exerce uma influência considerável sobre a motivação dos trabalhadores e também sobre sua satisfação e sua produtividade (Herzberg, 1966, 1980, 1996; Hackman e Suttle, 1977). Vale a pena, então, tentar compreender o sentido do trabalho hoje e determinar as características que deveria apresentar a fim de que ele tenha um sentido para aqueles que o realizam.

O objetivo deste artigo é identificar e comentar as características atribuídas a um trabalho que tem um sentido com o objetivo de orientar as decisões e as intervenções das pessoas responsáveis por processos de transformação que têm impacto sobre a organização do trabalho.

\section{A ORGANIZAÇÃO DO TRABALHO}

Os problemas de desempenho representam uma parte importante das preocupações dos administradores. Para resolvê-los, foram construídos mecanismos de gestão que visam identificar rapidamente os desvios de desempenho, determinar suas origens e corrigi-los. Apesar dos esforços investidos nas atividades de controle, vários problemas de produtividade persistem, fazendo os administradores acreditarem que o desempenho organizacional depende das decisões e dos comportamentos daqueles que realizam o trabalho e daqueles que são responsáveis pela administração de sua progressão. Entretanto, os esforços para reorientar os comportamentos fora dos padrões e para reforçar os comportamentos produtivos ainda não são suficientes para solucionar os problemas de produtividade enfrentados pelas empresas. Ketchum e Trist (1992) acreditam que os problemas de desempenho organizacional dependem da organização do trabalho e, mais precisamente, do grau de correspondência entre as características das pessoas e as propriedades das atividades desempenhadas.

O princípio que guia a organização do trabalho é o de modificar os comportamentos de tal forma que, gradualmente, os trabalhadores sejam conduzidos a desenvolver atitudes positivas com relação às funções executadas, à empresa que os emprega e a eles próprios. É o comprometimento com o trabalho que constitui o principal indicador de uma organização eficaz.

\section{A ORGANIZAÇÃO DO TRABALHO} DEVE OFERECER AOS TRABALHADORES

\section{A POSSIBILIDADE DE REALIZAR}

ALGO QUE TENHA SENTIDO, DE

PRATICAR E DE DESENVOLVER SUAS COMPETÊNCIAS, DE EXERCER SEUS JULGAMENTOS E SEU LIVRE-ARBÍTRIO,
DE CONHECER A EVOLUÇÃO DE SEUS DESEMPENHOS E DE SE AJUSTAR.

Vários modelos foram propostos para organizar o trabalho a fim de estimular o comprometimento. A seguir, descreveremos dois modelos: o das características do emprego de Hackman e Oldham e a concepção de sistemas sociotécnicos de Emery e Trist. Esses modelos constituem o ponto de partida dos resultados que serão apresentados em nossa pesquisa.

\section{Características do emprego}

Hackman e Oldham (1976) propuseram um modelo que tenta explicar como as interações, as características de um emprego e as diferenças individuais influenciam a motivação, a satisfação e a produtividade dos trabalhadores. A Figura 1 mostra as principais variáveis desse modelo.

Como mostra a figura, as cinco características do emprego conduzem a três estados psicológicos que engendram consequiências sobre as atitudes e os comportamentos das pessoas. As relações entre esses três conjuntos de variáveis seriam moderadas pela necessidade de crescimento da pessoa: um indivíduo com uma forte necessidade de crescimento seria mais sensível a um emprego enriquecido que um indivíduo com uma fraca necessidade. 
Três estados psicológicos teriam, assim, um impacto importante na motivação e na satisfação de uma pessoa no seu trabalho: o sentido que uma pessoa encontra na função exercida, o sentimento de responsabilidade que ela vivencia em relação aos resultados obtidos e o conhecimento de seu desempenho no trabalho. Para Hackman e Oldham, um trabalho tem sentido para uma pessoa quando ela o acha importante, útil e legítimo.

Segundo o modelo de Hackman e Oldham, três características contribuem para dar sentido ao trabalho:

1. A variedade das tarefas: a capacidade de um trabalho requerer uma variedade de tarefas que exijam uma variedade de competências.

2. A identidade do trabalho: a capacidade de um trabalho permitir a realização de algo do começo ao fim, com um resultado tangível, identificável.

3. O significado do trabalho: a capacidade de um trabalho ter um impacto significativo sobre o bem-estar ou sobre o trabalho de outras pessoas, seja na sua organização, seja no ambiente social.

A autonomia, ou seja, a capacidade de um trabalho deixar uma boa margem de liberdade, de independência e de discrição à pessoa para ela determinar as maneiras de realizá-lo, traz consigo o sentimento de responsabilidade pela realização das tarefas e pela obtenção dos objetivos fixados.

Finalmente, o feedback: a capacidade de realizar as tarefas resulta da informação que o indivíduo obtém diretamente do seu desempenho, permitindo-lhe fazer os ajustes necessários para que alcance os objetivos de desempenho.

A partir desse modelo, Hackman e Oldham elaboraram cinco princípios de organização do trabalho, buscando conferir uma ou várias características do emprego: a reunião de tarefas, a formação da unidade natural de trabalho - o que deu lugar à formação de equipes de trabalho (semi) autônomas -, o estabelecimento de relações do tipo cliente-fornecedor, o enriquecimento das tarefas e a colocação em prática de mecanismos de feedback sobre o desempenho.

\section{A concepção dos sistemas sociotécnicos}

A partir de 1950, Eric Trist, do Instituto Tavistock de Londres, mostrava que a insatisfação dos trabalhadores no setor de minas no Reino Unido era causada menos pelo salário do que pela organização do trabalho. Em suas pesquisas, ele procurou compreender quais são as condições que levam ao comprometimento do indivíduo no seu trabalho. Com seus colegas, propôs a chamada abordagem sociotécnica. Esse modelo visa organizar o trabalho de tal forma que o comprometimento dos indivíduos seja estimulado e que o desempenho organizacional possa ser melhorado. Trata-se, de fato, de organizar o trabalho de maneira a corresponder às motivações intrínsecas e extrínsecas dos trabalhadores (Ketchum e Trist, 1992). O Quadro 1 expõe as propriedades que tal trabalho apresenta.

A partir das pesquisas realizadas por Emery (1964, 1976) e Trist (1978), o trabalho deve apresentar seis propriedades para estimular o comprometimento daquele que o realiza:

1. A variedade e o desafio: o trabalho deve ser razoavelmente exigente - em outros termos que o de resistência física - e incluir variedade. Esse aspecto permite reconhecer o prazer que podem trazer o exercício das competências e a resolução dos problemas.

2. A aprendizagem contínua: o trabalho deve oferecer oportunidades de aprendizagem em uma base regular. Isso permite estimular a necessidade de crescimento pessoal.

3. Uma margem de manobra e a autonomia: o trabalho deve invocar a capacidade de decisão da pessoa. Deve-se reconhecer a necessidade de autonomia e o prazer retirado do exercício de julgamentos pessoais no trabalho.

4. O reconhecimento e o apoio: o trabalho deve ser reconhecido e apoiado pelos outros na organização. Esse aspecto estimula a necessidade de afiliação e vinculação.

5. Uma contribuição social que faz sentido: o trabalho deve permitir a união entre o exercício de atividades e suas conseqüências sociais. Isto contribui à construção da identidade social e protege a dignidade pessoal. Esse âmbito do trabalho reconhece o prazer de contribuir para a sociedade.

6. Um futuro desejável: o trabalho deve permitir a consideração de um futuro desejável, incluindo atividades de aperfeiçoamento e orientação profissional. Isso reconhece a esperança como um direito humano.

Quadro 1 - Propriedades do trabalho
\begin{tabular}{|l|l|}
\hline \multicolumn{1}{|c|}{ Condições do emprego } & \multicolumn{1}{c|}{ O trabalho em si } \\
\hline - Um salário justo e aceitável & - Variedade e desafios \\
- Estabilidade no emprego & - Aprendizagem contínua \\
- Vantagens apropriadas & - Margem de manobra, autonomia \\
- A segurança & - Reconhecimento e apoio \\
- A saúde & - Contribuição social que faz sentido \\
- Processos adequados & - Um futuro desejável \\
\hline
\end{tabular}

Fonte: Ketchum e Trist (1992, p. 11). 
Além desses aspectos intrínsecos ao trabalho, a concepção dos sistemas sociotécnicos considera vários aspectos extrínsecos que podem afetar o comprometimento no trabalho, tais como o salário, as condições físicas e materiais e as regras organizacionais. Embora existam diferenças individuais e fatores do contexto que podem influenciar o comprometimento com o trabalho, esses 12 fatores contribuem apreciavelmente para a melhoria da qualidade de vida no trabalho e para o desempenho organizacional.

Esses dois modelos têm vários pontos em comum. Entre outros, eles recomendam uma organização do trabalho que ofereça aos trabalhadores a possibilidade de realizar algo que tenha sentido, de praticar e de desenvolver suas competências, de exercer seus julgamentos e seu livre-arbítrio, de conhecer a evolução de seus desempenhos e de se ajustar. Parece-nos igualmente importante que os trabalhadores possam desenvolver o sentimento de vinculação e que possam trabalhar em condições apropriadas.

Desde a publicação desses modelos, as organizações têm vivido mudanças profundas, colocando o trabalho em questão. É justo então perguntar se as características enunciadas acima ainda são importantes atualmente. Nossas pesquisas sobre o sentido do trabalho, realizadas de 1994 a 1998, permitem responder a essa pergunta.

\section{PESQUISA DE CAMPO}

Para estudar o sentido do trabalho, dois métodos de pesquisa são utilizados: o questionário e a entrevista semiestruturada.

O questionário foi desenvolvido a partir do utilizado pelo grupo MOW (1987) e inclui cinco partes:
1. Opiniões e valores sobre o trabalho (6 perguntas).

2. Opiniões sobre a vida em geral (escala da interioridade/ exterioridade e confiança).

3. Informações pessoais (18 perguntas).

4. Expectativas com relação ao trabalho (6 perguntas).

5. Descrição do trabalho atual (10 perguntas).

O roteiro da entrevista possui nove perguntas por meio das quais podemos explicitar os múltiplos sentidos que os indivíduos atribuem ao trabalho, com o mínimo de intervenção possível dos pesquisadores. Em média, a duração das entrevistas foi de 40 minutos. Elas foram gravadas após o consentimento dos entrevistados.

Foram feitas duas amostras: uma de estudantes de administração e outra de administradores. A primeira amostra contém 542 estudantes inscritos na HEC em 1994, dos quais 269 são mulheres e 273, homens, com uma média de idade de 20,2 anos. A amostra de administradores contém 75 administradores, de médio e alto escalão em empresas de diversos setores, dos quais 36 são do Quebec e 39 da França. A média de idade dos administradores do Quebec é de 40,8 anos e dos administradores da França é de 42,1. Ao todo, são 24 mulheres: 12 do Quebec e 12 da França.

A amostragem foi composta com a colaboração de vários profissionais de recursos humanos, o que, certamente, afeta a validação externa dos resultados da nossa pesquisa. Porém, como ainda estamos num estágio de exploração, o objetivo visado não é de verificar hipóteses, mas de compreender melhor a problemática do sentido do trabalho para os administradores e de destacar hipóteses de pesquisa que poderão ser verificadas posteriormente mediante uma amostragem representativa.

Figura 1 - Modelo de características do emprego de Hackman e Oldham (1976)

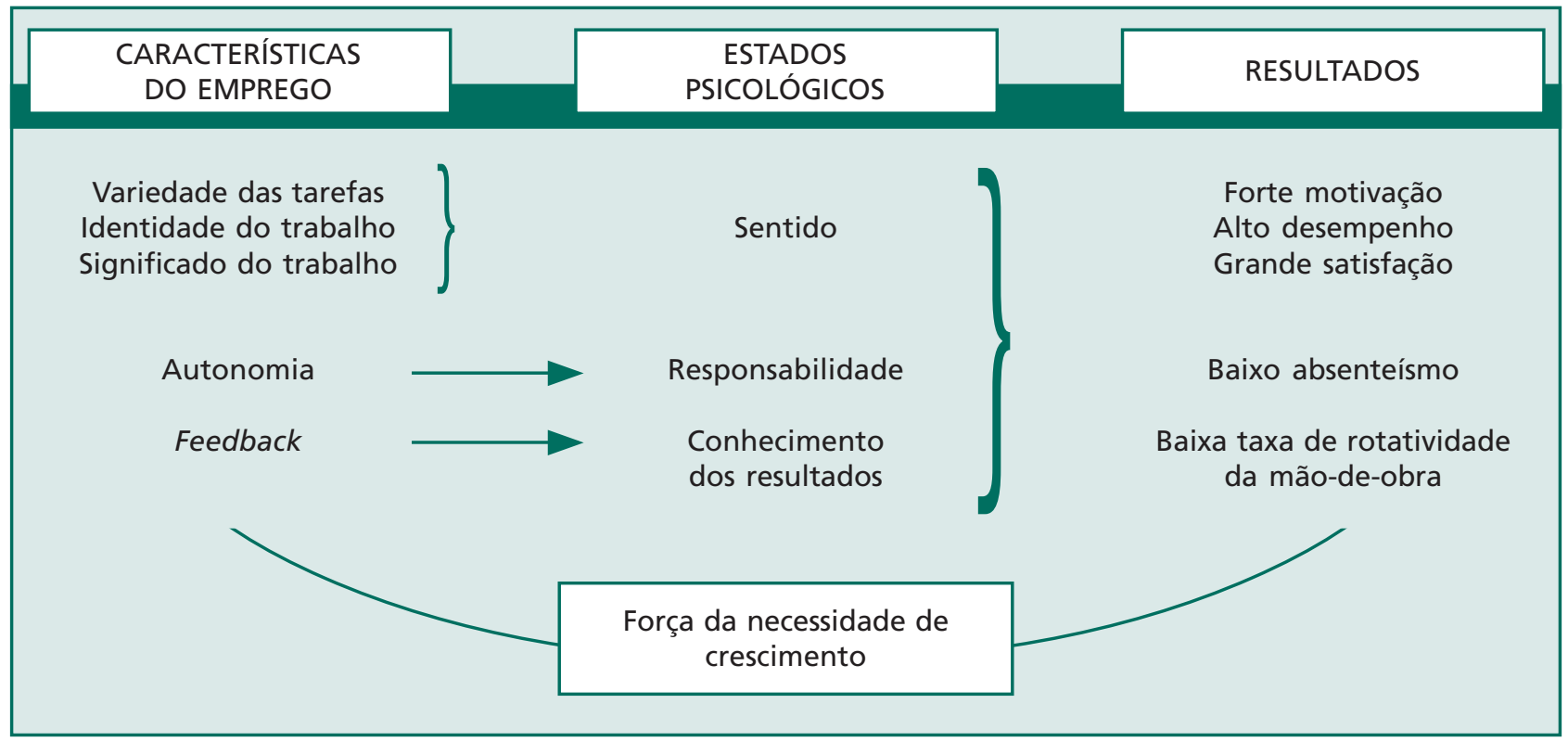




\section{0 que é o trabalho?}

Quando estudamos o trabalho, é importante saber o que os indivíduos pensam quando falam dele. De fato, o trabalho pode ser definido de várias maneiras. Segundo Brief e Nord (1990), o único elemento que reúne os múltiplos significados é: uma atividade que tem um objetivo. Geralmente, essa noção designa um gasto de energia mediante um conjunto de atividades coordenadas que visam produzir algo de útil (Fryer e Payne, 1984; Shepherdson, 1984). O trabalho pode ser agradável ou desagradável; ele pode ser associado ou não a trocas de natureza econômica. Ele pode ser executado ou não dentro de um emprego. De acordo com Fryer e Payne (1984), o trabalho seria uma atividade útil, determinada por um objetivo definido além do prazer gerado por sua execução.

Quanto ao emprego, trata-se da ocupação de uma pessoa, correspondendo ao conjunto de atividades remuneradas em um sistema organizado economicamente. A noção de emprego implica quase necessariamente a noção de salário e do consentimento do indivíduo em permitir que uma outra pessoa dite suas condições de trabalho.

Para conhecer as diferentes definições do trabalho, os pesquisadores afiliados ao grupo MOW - Meaning of Work - investigaram mais de 14.700 indivíduos em oito países: Bélgica, Inglaterra, Alemanha, Israel, Japão, Holanda, Estados Unidos e ex-Iugoslávia. England e Whiteley (1990), que fazem parte dessa equipe, encontraram seis padrões de definições do trabalho. Em todos, o salário constitui um elemento importante na definição, levando a crer que, para a maioria dos indivíduos, existem poucas diferenças entre trabalho e emprego. Entretanto, existem várias definições do trabalho que se referem a diferentes sistemas de representações, como indicado no Quadro 2.

Os padrões A, B e C correspondem a concepções positivas do trabalho. O padrão A descreve o trabalho como

Quadro 2 - Padrões de definição do trabalho determinados por England e Whiteley (1990)

\begin{tabular}{|c|c|c|}
\hline $\begin{array}{c}\text { Padrão A } \\
10,6 \%\end{array}$ & $\begin{array}{c}\text { Padrão B } \\
27,6 \%\end{array}$ & $\begin{array}{c}\text { Padrão C } \\
17,6 \%\end{array}$ \\
\hline \multirow[t]{5}{*}{$\begin{array}{l}\text { - Acrescenta valor a qualquer } \\
\text { coisa } \\
\text { - Você deve prestar conta disto } \\
\text { - Faz parte de suas tarefas } \\
\text { - Você recebe dinheiro para } \\
\text { fazer isto }\end{array}$} & $\begin{array}{l}\text { - Realizando isto, você tem o } \\
\text { sentimento de vinculação } \\
\text { - Você recebe dinheiro para } \\
\text { realizar isto } \\
\text { - Você faz para contribuir à } \\
\text { sociedade } \\
\text { - Faz parte de suas tarefas }\end{array}$ & $\begin{array}{l}\text { - Outros se beneficiam disto } \\
\text { - Você recebe dinheiro para } \\
\text { realizar isto } \\
\text { - Você faz para contribuir à } \\
\text { sociedade } \\
\text { - Acrescenta valor a qualquer coisa } \\
\text { - É fisicamente exigente }\end{array}$ \\
\hline & $\begin{array}{c}\text { Padrão D } \\
21,7 \%\end{array}$ & $\begin{array}{c}\text { Padrão E } \\
10,6 \%\end{array}$ \\
\hline & $\begin{array}{l}\text { - Você recebe dinheiro para } \\
\text { realizar isto } \\
\text { - Faz parte de suas tarefas } \\
\text { - Você realiza em um local de } \\
\text { trabalho } \\
\text { - Você deve fazer isto } \\
\text { - Alguém Ihe diz o que fazer } \\
\text { - Não é agradável }\end{array}$ & $\begin{array}{l}\text { - É mentalmente exigente } \\
\text { - É fisicamente exigente } \\
\text { - Você recebe dinheiro para } \\
\text { fazer isto } \\
\text { - Faz parte de suas tarefas } \\
\text { - Isto não está agradando }\end{array}$ \\
\hline & & $\begin{array}{c}\text { Padrão F } \\
11,8 \%\end{array}$ \\
\hline & & $\begin{array}{l}\text { - Você realiza seguindo um horário } \\
\text { - Você realiza em um local de } \\
\text { trabalho } \\
\text { - Você recebe dinheiro para fazer } \\
\text { isto } \\
\text { - Faz parte de suas tarefas }\end{array}$ \\
\hline
\end{tabular}


uma atividade, geralmente agradável, que acrescenta um valor a alguma coisa e pela qual tem que se prestar conta dos resultados. O padrão B parece ser a definição mais comum: ele descreve o trabalho como uma atividade que proporciona a quem o realiza um sentimento de vinculação e que traz uma contribuição para a sociedade. O padrão $\mathrm{C}$ define o trabalho como uma atividade que beneficia aos outros, que traz uma contribuição para a sociedade e que gera um valor agregado. Esses três padrões valorizam o caráter social do trabalho.

Os padrões $\mathrm{D}$ e $\mathrm{E}$ correspondem às concepções negativas do trabalho. O padrão D define o trabalho como uma atividade que não é agradável, mas que deve ser realizada por alguém em um lugar específico, sob a supervisão de uma outra pessoa. O padrão $\mathrm{E}$ descreve o trabalho como uma atividade desagradável que comporta exigências físicas e mentais. Como podemos facilmente observar, esses dois padrões apresentam o trabalho como uma atividade que somos obrigados a realizar para ganhar a vida.

$\mathrm{O}$ padrão $\mathrm{F}$ apresenta uma concepção neutra do trabalho: uma atividade que segue um horário regular, em um local de trabalho e pela qual se recebe um salário.

De acordo com England e Whiteley (1990), é no Japão que está concentrada a maior porcentagem de trabalhadores que têm uma concepção positiva do trabalho. Com exceção da Alemanha e dos Estados Unidos, eles encontraram uma pequena diferença nas porcentagens de trabalhadores que têm uma concepção positiva comparativamente às outras concepções. Na Alemanha e nos Estados Unidos, a maioria de trabalhadores tem uma concepção neutra do trabalho.

Para determinar os padrões de definição que podemos encontrar no Quebec e na França, apresentamos os mesmos elementos de definição aos indivíduos das duas amostras e pedimos que eles os ordenassem segundo a importância atribuída. No Quadro 3, apresentamos as respostas dos estudantes e dos administradores.

Os estudantes pesquisados possuem uma concepção positiva do trabalho; eles têm tendência a definir o trabalho como uma atividade lucrativa que lhes permite melhorar, que acrescenta um valor a alguma coisa, que lhes dá um sentimento de vinculação e que contribui à sociedade.

Os administradores pesquisados também possuem uma concepção positiva do trabalho. Os administradores do Quebec definem o trabalho como uma atividade lucrativa que acrescenta um valor a alguma coisa, que é exigente mentalmente, que contribui à sociedade e pela qual eles têm que prestar contas. Os administradores franceses definem o trabalho como uma atividade que acrescenta um valor a alguma coisa, que contribui à sociedade, que lhes permite melhorar, pela qual eles recebem um salário e que lhes dá um sentimento de vinculação.

Comparado aos padrões de definição encontrados por England e Whiteley, o padrão que resulta de nossas pesquisas se aproxima dos padrões B e C. As pessoas pes-

Quadro 3 - Classificação da importância dos elementos de definição do trabalho

escolhidos por estudantes de administração e administradores do Quebec e da França

\begin{tabular}{|l|c|c|c|}
\hline \multirow{2}{*}{ O que eu faço é trabalho se: } & $\begin{array}{c}\text { Estudantes } \\
(\mathrm{n} 1=542)\end{array}$ & $\begin{array}{c}\text { Administradores do Quebec } \\
(\mathrm{n} 2=36)\end{array}$ & $\begin{array}{c}\text { Administradores franceses } \\
(\mathrm{n} 3=39)\end{array}$ \\
\hline Eu faço em um local de trabalho & 9,0 & 10,5 & 13,0 \\
\hline Alguém me diz o que fazer & 13,0 & 10,5 & 12,0 \\
\hline É fisicamente exigente & 14,0 & 15,0 & 14,0 \\
\hline Faz parte de minhas tarefas & 5,0 & 6,5 & 9,0 \\
\hline Eu faço para contribuir à sociedade & 6,0 & 4,5 & 2,0 \\
\hline $\begin{array}{l}\text { Eu tenho um sentimento de } \\
\text { vinculação enquanto realizo }\end{array}$ & 4,0 & 12,5 & 5,0 \\
\hline É mentalmente exigente & 7,0 & 3,0 & 8,0 \\
\hline $\begin{array}{l}\text { Eu faço isto em um dado } \\
\text { momento (por ex.: das 8 h às } 17 \mathrm{~h})\end{array}$ & 12,0 & 14,0 & 11,0 \\
\hline Acrescenta valor a alguma coisa & 3,0 & 2,0 & 1,0 \\
\hline Não é agradável & 15,0 & 12,5 & 15,0 \\
\hline Eu recebo dinheiro para realizar & 1,0 & 1,0 & 4,0 \\
\hline Eu tenho que prestar contas & 8,0 & 4,5 & 7,0 \\
\hline Eu sou obrigado(a) a realizar & 11,0 & 8,0 & 10,0 \\
\hline Outros se beneficiam & 10,0 & 9,0 & 6,0 \\
\hline Permite que eu melhore & 2,0 & 6,5 & 3,0 \\
\hline
\end{tabular}


quisadas, sejam elas jovens ou não, no Quebec ou na França, possuem uma concepção positiva do trabalho.

Por trabalho, os indivíduos de nossas amostragens compreendem uma atividade remunerada, que apresen-

\section{É IMPORTANTE QUE A}

\section{ORGANIZAÇÃO DAS TAREFAS}

E DAS ATIVIDADES TORNE-SE

FAVORÁVEL À EFICIÊNCIA E QUE

OS OBJETIVOS VISADOS E OS

RESULTADOS ESPERADOS SEJAM

\section{CLAROS E SIGNIFICATIVOS PARA}

\section{AS PESSOAS QUE O REALIZAM.}

ta um valor agregado, que lhes permite melhorar e que traz uma contribuição para a sociedade. Essa concepção prediz as características que deveria ter um trabalho que tem sentido.

\section{Características de um trabalho que tem sentido}

\section{Para os estudantes de administração}

Os estudantes de administração têm uma concepção positiva do trabalho. Para conhecer as razões que os motivam a trabalhar, eles classificaram os tópicos geralmente mencionados. Dado o número de indivíduos, foi possível realizar uma análise das respostas por meio da análise dos componentes principais. Cinco motivos resultaram dessa análise:

1. Para realizar-se e atualizar seu potencial: trabalhar é interessante e satisfaz em si, permite exercer a criatividade e realizar-se, possibilita concretizar e desenvolver seus talentos.

2. Para adquirir segurança e ser autônomo: trabalhar permite suprir as necessidades de base, dá sentimento de segurança, possibilita ser autônomo e independente.

3. Para relacionar-se com os outros e ter o sentimento de vinculação: trabalhar permite ter contatos interessantes com os outros, possibilita fazer parte de um grupo.

4. Para prestar um serviço e fazer sua contribuição à sociedade: trabalhar dá a oportunidade de prestar um serviço aos outros, permite contribuir à melhoria da qualidade de vida da comunidade.

5. Para ter um sentido: trabalhar mantém ocupado, é um modo de preencher as funções espirituais, dá um sentido à vida.

A simples leitura desses resultados mostra o trabalho como um meio de emancipação. Pelo salário que ele possi- bilita, o indivíduo afirma sua independência; por meio de suas atividades, o trabalho desenvolve o potencial e fortalece a identidade dos indivíduos; pelas relações que o trabalho gera, ele consolida a identidade social; pelos seus resultados, permite ao indivíduo contribuir ao mundo e dar um sentido à sua existência. $\mathrm{O}$ trabalho, assim apresentado pelos estudantes, é muito mais que um simples "ganha-pão".

Para compreender o sentido que os estudantes dão ao trabalho, eles classificaram em ordem de importância as características do trabalho que eles procuram ao final dos estudos. A análise dos componentes principais permitiu determinar três conjuntos de características:

1. Boas condições de trabalho: um trabalho que corresponda às competências do empregado, que forneça oportunidades de valorização pessoal, um horário de trabalho conveniente, um bom salário, além de condições que preservem a saúde.

2. Oportunidades para aprender e prestar serviços: muitas oportunidades para aprender, boas relações com os outros, oportunidades para prestar serviços.

3. Um trabalho interessante, variado, com muita autonomia: um trabalho de que realmente gostem, muita variedade, poder decidir como fazê-lo.

As características do trabalho que eles procuram são coerentes com os motivos que lhes estimulam a trabalhar. É interessante observar que os estudantes associam as exigências do trabalho em termos de competências e de oportunidades de valorização pessoal às condições de trabalho. Mais da metade dos estudantes pesquisados tinha um emprego em tempo parcial no momento desta pesquisa. Poderia-se acreditar que a concepção que eles fazem do trabalho seja o reflexo da falta de experiência no mercado de trabalho e que o exercício das funções associadas à administração poderia fazer a maioria deles desenvolver um outro ponto de vista. Isso é possível, mas não há como verificar.

\section{Para os administradores}

Também entrevistamos administradores, de níveis médio e superior, para conhecer o sentido que eles dão ao trabalho e as características que nele procuram.

Foram entrevistados administradores no Quebec e na França a fim de observar se existe ou não a influência de diferenças culturais. O Quadro 4 mostra os resultados. As respostas estão apresentadas segundo a classificação de freqüências.

O que nos surpreende é a semelhança entre as respostas fornecidas pelos dois grupos. Sejam eles do Quebec, sejam da França, os administradores têm uma concepção positiva do trabalho, o que confirma os resultados obtidos pelo grupo MOW (1987) com populações semelhantes. Se fizermos um julgamento com base nos resultados obtidos, um trabalho tem sentido se for feito de maneira eficiente, se conduz a alguma coisa, se beneficia a outras pessoas, se ele corresponde aos inte- 
resses e às competências das pessoas, se ele permite aprender, realizar-se e superar-se e se ele permite exprimir-se e exercer seu poder.

Quando perguntamos aos administradores do que eles sentem ou sentiriam mais falta se eles não trabalhassem mais, eles tenderam a responder: ter alguma coisa para fazer, ser produtivo, sentir-se útil, ter dignidade pessoal, manter as relações com os outros, o sentimento de fazer parte de um grupo e o salário.

\section{ORGANIZAR O TRABALHO PARA QUE ELE TENHA UM SENTIDO}

Os resultados de nossa pesquisa permitem determinar as características do trabalho que tem um sentido. Em um primeiro momento, elas não são sensivelmente diferentes das características apresentadas por Hackman e Oldham ou por Emery e Trist. Algumas diferenças merecem ser ressaltadas. Podemos relacioná-las aos princípi-

Quadro 4 - Conteúdo das respostas mais freqüentes dos administradores do Quebec e da França nas entrevistas

\begin{tabular}{|c|c|c|}
\hline & $\begin{array}{l}\text { Administradores do Quebec } \\
\qquad(\mathrm{n} 2=36)\end{array}$ & $\begin{array}{l}\text { Administradores da França } \\
\qquad(n 3=39)\end{array}$ \\
\hline $\begin{array}{l}\text { Um trabalho tem } \\
\text { sentido se... }\end{array}$ & $\begin{array}{l}\text { - Permite atualizar seu potencial, } \\
\text { aprender e se ultrapassar } \\
\text { - É interessante, dá prazer } \\
\text { - Beneficia aos outros } \\
\text { - Faz sentir-se útil, valorizado } \\
\text { - Feito de maneira eficiente, leva a } \\
\text { algum lugar } \\
\text { - Feito com outras pessoas }\end{array}$ & $\begin{array}{l}\text { - Feito de maneira eficiente, leva a } \\
\text { algum lugar } \\
\text { - Beneficia aos outros } \\
\text { - Permite atualizar seu potencial, } \\
\text { aprender e se ultrapassar } \\
\text { - É interessante, dá prazer } \\
\text { - Permite se expressar, exercer seu } \\
\text { poder }\end{array}$ \\
\hline $\begin{array}{l}\text { Um trabalho não tem } \\
\text { sentido se... }\end{array}$ & $\begin{array}{l}\text { - Feito de maneira ineficiente, leva a } \\
\text { lugar algum } \\
\text { - Rotineiro } \\
\text { - Inútil, não beneficia ninguém } \\
\text { - Não corresponde às suas } \\
\text { competências nem aos seus interesses } \\
\text { - É desvalorizador } \\
\text { - Não serve para prover as necessidades } \\
\text { básicas, trabalhar só pelo salário } \\
\text { - Feito em um lugar que prega valores } \\
\text { que não são compartilhados por você }\end{array}$ & $\begin{array}{l}\text { - Feito de maneira ineficiente, leva a } \\
\text { lugar algum } \\
\text { - Rotineiro } \\
\text { - Inútil, não beneficia ninguém } \\
\text { - Não corresponde às suas } \\
\text { competências nem aos seus } \\
\text { interesses } \\
\text { - Feito em um lugar que prega valores } \\
\text { que não são compartilhados por você } \\
\text { - Feito sem interesse e sem prazer } \\
\text { - Não permite se expressar nem } \\
\text { exercer seu poder }\end{array}$ \\
\hline o que eu procuro... & $\begin{array}{l}\text { - Um trabalho interessante, com muita } \\
\text { autonomia } \\
\text { - A possibilidade de me realizar e } \\
\text { desenvolver meus talentos, de } \\
\text { exercer minha criatividade e me } \\
\text { completar } \\
\text { - Boas condições de trabalho } \\
\text { - Poder dar um sentido à minha vida }\end{array}$ & $\begin{array}{l}\text { - A possibilidade de me realizar e } \\
\text { desenvolver meus talentos, de exercer } \\
\text { minha criatividade e me completar } \\
\text { - Contatos interessantes com outras } \\
\text { pessoas e o sentimento de vinculação } \\
\text { - Boas condições de trabalho } \\
\text { - A possibilidade de me expressar e } \\
\text { exercer meu poder }\end{array}$ \\
\hline $\begin{array}{l}\text { Do que eu sentiria } \\
\text { mais falta... }\end{array}$ & $\begin{array}{l}\text { - Sentir-me útil, dignidade pessoal } \\
\text { - As relações com os outros, o } \\
\text { sentimento de fazer parte de um } \\
\text { grupo } \\
\text { - Ter algo para fazer } \\
\text { - Fazer algo de produtivo } \\
\text { - O salário }\end{array}$ & $\begin{array}{l}\text { - Ter algo para fazer } \\
\text { - Fazer algo de produtivo } \\
\text { - Sentir-me útil, dignidade pessoal } \\
\text { - As relações com os outros, o } \\
\text { sentimento de fazer parte de um } \\
\text { grupo } \\
\text { - O salário }\end{array}$ \\
\hline
\end{tabular}


os de organização, como fizeram Hackman e Oldham, a fim de sugerir formas concretas de organizar o trabalho durante as transformações organizacionais.

\section{Um trabalho que tem sentido é feito} de maneira eficiente e leva a alguma coisa

$\mathrm{O}$ trabalho é uma atividade produtiva que agrega valor a alguma coisa: temos aqui um aspecto que é novo, comparativamente aos modelos de organização do trabalho apresentados anteriormente. As pessoas entrevistadas consideram que é importante que o trabalho seja organizado de maneira eficiente, cuja realização conduza a resultados úteis, gastando-se energia de maneira rentável. Em sua forma negativa, essa característica do trabalho contribui extensivamente à sua absurdez.

\section{O FATO DE FAZER UM}

\section{TRABALHO QUE NÃO COMPORTA}

\section{NENHUM INTERESSE HUMANO,}

\section{EM UM MEIO AMBIENTE}

\section{ONDE AS RELAÇÕES SÃO}

\section{SUPERFICIAIS, CONTRIBUI}

\section{PARA TORNÁ-LO ABSURDO.}

A maneira como os indivíduos trabalham e o que eles produzem têm um impacto sobre o que pensam e na maneira como percebem sua liberdade e sua independência. $\mathrm{O}$ processo de trabalho, assim como seu fruto, ajuda o indivíduo a descobrir e formar sua identidade. Acontece que a organização do trabalho em si mesma conta muito: é importante que a organização das tarefas e das atividades torne-se favorável à eficiência e que os objetivos visados, assim como os resultados esperados, sejam claros e significativos para as pessoas que o realizam.

\section{Um trabalho que tem sentido}

\section{é intrinsecamente satisfatório}

O prazer e o sentimento de realização que podem ser obtidos na execução de tarefas dão um sentido ao trabalho. A execução de tarefas permite exercer seus talentos e suas competências, resolver problemas, fazer novas experiências, aprender novas competências, resumindo, realizar-se, atualizar seu potencial e aumentar sua autonomia. Essas características são encontradas nos dois modelos apresentados previamente.

O interesse do trabalho em si mesmo parece estar associado, por um lado, ao grau de correspondência entre as exigências do trabalho e, por outro lado, ao conjunto de valores, de interesses e de competências do indivíduo. Efetivamente, muitas pessoas relataram que um trabalho que tem sentido é aquele que corresponde à personalidade, aos talentos e aos desejos delas.

O interesse de tal trabalho também se origina das possibilidades que ele oferece para provar seus valores pessoais e para realizar suas ambições. $\mathrm{O}$ trabalho permite realização, dando oportunidades para vencer desafios ou perseguir ideais.

O interesse do trabalho também resulta das possibilidades de desenvolver sua autonomia e perceber seu senso de responsabilidades. Isso é oferecido por uma organização que deixa os empregados serem os administradores de suas atividades e que, por meio da presença de mecanismos de feedback, lhes mantém informados sobre a evolução do seu desempenho e lhes permite fazer os ajustes necessários para melhorá-lo.

$\mathrm{O}$ fato de que o indivíduo tem que resolver problemas durante a realização do trabalho e exercer seu julgamento para tomar decisões relativas à organização das suas atividades reforça o sentimento de competência e eficácia pessoal; isso tem uma influência direta não somente no desenvolvimento da autonomia pessoal mas também na motivação. Além disso, o fato de ter que resolver problemas e vencer dificuldades estimula a criatividade dos indivíduos. Finalmente, a presença de mecanismos de feedback mantém os empregados informados sobre a evolução do desempenho deles, facilita a regulação das atividades e estimula o senso de responsabilidades.

\section{Um trabalho que tem}

\section{sentido é moralmente aceitável}

O trabalho é uma atividade que se inscreve no desenvolvimento de uma sociedade; ele deve, conseqüentemente, respeitar as prescrições relativas ao dever e ao saber viver em sociedade, tanto na sua execução como nos objetivos que ele almeja e nas relações que ele estabelece. Em outras palavras, o trabalho deve ser feito de maneira socialmente responsável. Essa idéia foi desenvolvida especialmente pela abordagem sociotécnica. Ela foi expressa claramente por vários administradores que encontramos e que exprimiram um certo mal-estar em trabalhar em um meio que exalta valores que eles não compartilham, que tolera práticas desrespeitosas, injustas, contraprodutivas ou até mesmo desonestas ou imorais.

Vários administradores se mostraram preocupados com as contribuições do trabalho para a sociedade. $\mathrm{O}$ fato de fazer um trabalho que não serve para nada, que não comporta nenhum interesse humano, em um meio ambiente onde as relações são superficiais, contribui para tornar o trabalho absurdo. É por isso que é necessário também considerar, na organização do trabalho, as implicações dele para si mesmo, para os outros e para a sociedade em geral. Finalmente, para muitos administradores, o 
trabalho é um dos meios para transcender seus interesses particulares, dedicando-se a uma causa importante e significativa. Isso corresponde, então, a uma verdadeira busca do sentido nas organizações (Pauchant, 1996).

\section{Um trabalho que tem sentido é fonte}

de experiências de relações humanas satisfatórias

$\mathrm{O}$ trabalho é também uma atividade que coloca as pessoas em relação umas com as outras, o que contribui para o desenvolvimento da identidade delas. Essa característica aparece de maneira consistente nas pesquisas - sinal de sua importância para a organização do trabalho. Vários administradores reportaram que um trabalho que tem sentido é um trabalho que lhes permite encontrar pessoas de qualidade, seja no seu departamento, na sua empresa ou nos ambientes empresariais, pessoas com quem os contatos podem ser francos, honestos, com quem se pode ter prazer em trabalhar, mesmo em projetos difíceis. Um trabalho que tem muito sentido permite ajudar os outros a resolver seus problemas, prestar-lhes um serviço, ter um impacto sobre as decisões tomadas pelos dirigentes, ser reconhecido por suas habilidades e contribuições ao sucesso dos negócios, etc. As satisfações podem ser adquiridas na associação com os outros no trabalho e durante as trocas com os clientes, superiores e colaboradores. A satisfação não é retirada somente dos serviços prestados mas também das afiliações encontradas no seu trabalho.

$\mathrm{O}$ fato de estar em contato com os outros, de manter relações numerosas, e às vezes intensas, age como um verdadeiro estimulante para si mesmo, não somente para o desenvolvimento de sua identidade pessoal e social mas também para o desenvolvimento de laços de afeição duráveis, procurando por vezes a segurança e a autonomia pessoal. Contribuindo para o desenvolvimento dos laços sociais, o trabalho permite aos administradores escapar do sentimento de isolamento, viver melhor sua solidão e encontrar seu lugar na comunidade. Neste sentido, o trabalho permite passar por cima dos problemas existenciais, como a solidão e a morte (Fox, 1980).

\section{Um trabalho que tem sentido}

\section{garante a segurança e a autonomia}

$\mathrm{O}$ trabalho está claramente associado à noção de emprego; o salário que ele propicia permite prover as necessidades de base, dá um sentimento de segurança e possibilita ser autônomo e independente. Na verdade, geralmente, associamos o salário a elementos de prestígio, enquanto está claro aqui que o salário é associado principalmente aos elementos de segurança e de independência. Mais ainda, para a maioria dos administradores, ganhar a vida é sinônimo de ganhar o respeito dos outros e, assim, preservar sua dignidade pessoal aos olhos dos outros. Assim como no modelo apresentado por Ketchum e Trist, o salário parece constituir um elemento de organização que deve ser distinguido das outras condições de trabalho.
Isso não nos impede de ter que considerar as condições nas quais o trabalho se realiza, pois elas são importantes aos olhos dos trabalhadores. Além do mais, para os administradores entrevistados, as exigências de desempenho e o estresse são os principais fatores que contribuem para deteriorar a experiência deles no trabalho. Além disso, muitos procuram um equilíbrio entre vida profissional e vida privada.

\section{Um trabalho que tem sentido}

é um trabalho que mantém ocupado

O trabalho também é uma atividade programada, com um começo e um fim, com horários e uma rotina diária. Ele estrutura o tempo: os dias, as semanas, os meses, os anos, a vida profissional. Ele dá sentido aos períodos de férias. É, dessa maneira, uma atividade que estrutura e permite organizar a vida diária e, por extensão, a história

\section{UM TRABALHO QUE TEM}

\section{SENTIDO PERMITE ENCONTRAR \\ PESSOAS COM QUEM OS CONTATOS}

\section{PODEM SER FRANCOS, HONESTOS,

COM QUEM SE PODE TER PRAZER

\section{EM TRABALHAR, MESMO \\ EM PROJETOS DIFÍCEIS.}

pessoal. Isso é ainda mais marcante para os administradores que perderam seu emprego. Estes últimos dizem que o trabalho é uma necessidade, uma dimensão importante de suas vidas, que lhes ajuda a se situar, que ocupa o tempo da vida e que lhe dá um sentido, sobretudo quando eles têm a possibilidade de escolher seu caminho e fazer qualquer coisa que esteja de acordo com suas personalidades e valores. Esses resultados confirmam os de Warr (1987), que pesquisou os desempregados norte-americanos. Por outro lado, ter um trabalho significa estar ocupado fazendo alguma coisa; os administradores relataram que ser pago para não fazer nada não tem sentido. O que significa que, mesmo empregado, pode-se sofrer por falta de trabalho.

Analisando a questão, é verdade que o trabalho continua sendo uma maneira excelente de organizar o tempo e de se manter ocupado. As ocupações por ele engendradas proporcionam uma estrutura de defesa contra a ansiedade da morte e do vazio. Foi pensando nos trabalhos de Jacques (1978) sobre os sistemas sociais como defesas que surgiu essa idéia. Ela também encontra eco nas pesquisas realizadas por Bracke e Bugental (1996), por 
Pauchant (1996) e por Weil (1951). Notamos claramente, durante as entrevistas, que o trabalho representa para os administradores algo a fazer, que torna legítimos os períodos de descanso e de férias, que preenche os dias, as semanas, os meses e os anos de sua existência e que ritma o tempo da vida. Alguns também encontram palavras para expressar a que ponto eles se sentem incomodados e envergonhados de não ter nada o que fazer durante o dia ou culpados de não poder ganhar a vida. Tais conteúdos evocam as tensões que podemos sentir em face do vazio.

\section{IMPLICAÇÕES PARA A TRANSFORMAÇÃO DAS ORGANIZAÇÕES E A ORGANIZAÇÃO DO TRABALHO}

No momento em que os administradores sonham em fazer mudanças nas atividades do trabalho, deveriam projetar meios para revalorizar o trabalho e lhe dar um sentido. No Quadro 5, apresentamos uma síntese das características do trabalho e os 14 princípios de organização. Inspirados nos modelos apresentados no início deste artigo e a partir de nossas pesquisas, esses princípios representam recursos concretos para organizar o trabalho.

Para que um trabalho tenha sentido, é importante que quem o realize saiba para onde ele conduz; em outras palavras, é essencial que os objetivos sejam claros e valorizados e que os resultados tenham valor aos olhos de quem o realiza.

Para que um trabalho seja satisfatório para quem o realiza, parece ser importante que ele apele para suas competências. Além disso, parece relevante que o trabalhador tenha a oportunidade de testar suas capacidades, com o objetivo de estimular suas necessidades de crescimento pessoal e seu senso de responsabilidade. Vários recursos podem ser considerados: a presença de desafios, a autonomia na administração das atividades e os mecanismos de feedback sobre o desempenho são freqüentemente citados.

O trabalho deve se realizar segundo as regras do de-

Quadro 5 - Síntese das características de um trabalho que tem sentido associadas aos princípios de organização

\begin{tabular}{|c|c|c|}
\hline $\begin{array}{l}\text { Um trabalho que tem } \\
\text { sentido é um que... }\end{array}$ & $\begin{array}{l}\text { Características } \\
\text { do trabalho }\end{array}$ & $\begin{array}{c}\text { Princípios } \\
\text { da organização }\end{array}$ \\
\hline \multirow{2}{*}{$\begin{array}{l}\text { É realizado de forma } \\
\text { eficiente e leva a um } \\
\text { resultado }\end{array}$} & Finalidade & $\begin{array}{l}\text { Clareza e importância dos objetivos } \\
\text { Utilidade, valor dos resultados }\end{array}$ \\
\hline & Eficiência & Racionalidade das tarefas \\
\hline \multirow[t]{4}{*}{$\begin{array}{l}\text { É intrinsecamente } \\
\text { satisfatório }\end{array}$} & $\begin{array}{l}\text { Aprendizagem e desenvolvimento das } \\
\text { competências }\end{array}$ & $\begin{array}{l}\text { Correspondência entre as exigências do } \\
\text { trabalho e as competências da pessoa }\end{array}$ \\
\hline & Realização e atualização & Desafios e ideais \\
\hline & Criatividade e autonomia & $\begin{array}{l}\text { Margem de manobra sobre a } \\
\text { administração das atividades e a } \\
\text { resolução dos problemas }\end{array}$ \\
\hline & Responsabilidade & Feedback sobre o desempenho \\
\hline \multirow[t]{2}{*}{ É moralmente aceitável } & $\begin{array}{l}\text { Retidão das práticas sociais e } \\
\text { organizacionais }\end{array}$ & $\begin{array}{l}\text { Regras do dever e do saber viver em } \\
\text { sociedade }\end{array}$ \\
\hline & Contribuição social & Valores morais, éticos e espirituais \\
\hline \multirow{2}{*}{$\begin{array}{l}\text { É fonte de experiências } \\
\text { de relações humanas } \\
\text { satisfatórias }\end{array}$} & Afiliação e vinculação & Trabalho em equipe \\
\hline & Serviço aos outros & Relações do tipo cliente-fornecedor \\
\hline \multirow{2}{*}{$\begin{array}{l}\text { Garante a segurança e a } \\
\text { autonomia }\end{array}$} & Independência financeira & Salário apropriado e justo \\
\hline & Saúde e segurança & Boas condições de trabalho \\
\hline Mantém ocupado & Ocupação & Carga de trabalho adequada \\
\hline
\end{tabular}


ver e do saber viver em sociedade e deveria ser inspirado pelos valores morais, éticos e espirituais. Examinar as regras e os valores que subentendem as práticas sociais e organizacionais que envolvem o trabalho pode parecer supérfluo para alguns, mas isso é inevitável em um contexto de diversidade cultural e de promoção das liberdades individuais.

$\mathrm{O}$ trabalho em equipe e o desenvolvimento de relações profissionais positivas, do tipo cliente-fornecedor, são dois princípios que incentivam o desenvolvimento do sentimento de vinculação e de cooperação dentro dos grupos de trabalho.

Finalmente, não se deve cometer negligência ao colocar em prática condições de trabalho que proporcionem aos trabalhadores os sentimentos de segurança e de autonomia necessários para seu desenvolvimento: os salários e as condições de trabalho devem ser estudados seriamente. Além disso, é importante que a carga de trabalho seja adequada, pois não existe nada mais absurdo do que ser pago para não fazer nada. Esta última condição nos leva de volta à primeira, indicando a preocupação com relação à utilidade e à eficácia que apresentam os indivíduos com quem nos encontramos (Morin, 1996).

Os momentos de transformação organizacional constituem potencialmente uma oportunidade para reorganizar o trabalho de tal forma que a qualidade de vida e a eficácia organizacional sejam melhoradas. Desejamos que a apresentação dos resultados de nossas pesquisas possam ajudar os administradores a melhorar suas práticas de gestão. $\bigcirc$

\section{BIBLIOGRAFIA}

BRACKE, P. E., BUGENTAL, J. F. T. La dépendance existentielle: traiter le comportement de type A et la boulotmanie. In: PAUCHANT, T. C. et coll. (Coord.). La quête du sens: gérer nos organisations pour la santé des personnes, de nos sociétés et de la nature. Québec : Éditions de l'organisation, 1996. (Collection Manpower, p. 73-100)

BRIEF, A. P., NORD, W. R. Meaning of occupational work. Toronto : Lexington Books, 1990.

EMERY, F. Report on the Hunsfoss Project. London : Tavistock, 1964. Tavistock Document Series.

EMERY, F. Future we are in. Leiden : Martinus Nijhoff, 1976.

ENGLAND, G. W. The patterning of work meanings which are coterminous with work outcome levels for individuals in Japan. Applied Psychology : An International Review, v. 39, n. 1, p. 29-45, 1990.

ENGLAND, G. W., WHITELEY, W. T. Cross-national meanings of working. In: BRIEF, A. P., NORD, W. R. Meanings of occupational work. Toronto : Lexington Books, 1990. p. 65-106.

FOX, A. The meaning of work. In: ESLAND, G., SALAMAN, G. The politics of work and organizations. Milton Keyes : Open University Press, 1980.

FRYER, D., PAYNE, R. Working definitions. Quality of Working Life, v. 1, n. 5, p. 13-15, 1984

HACKMAN, J. R., OLDHAM, G. R. Motivation through the design of work: test of a theory. Organizational Behavior and Human Performance, v. 16, p. 250-279, 1976.
HACKMAN, J. R., SUTTLE, J. L. Improving life at work. Glenview, III : Scott, Foresman, and Co., 1977.

HERZBERG, F. I. Work and the nature of man. Cleveland : World Publishing Co., 1966.

HERZBERG, F. I. Maximizing work and minimizing labor. Industry Week, v. 206, n. 8, p. 61-64, 1980.

HERZBERG, F. I. Les quatre questions existentielles: leur effet sur la motivation humaine et le comportement organisationnel. In: PAUCHANT, T. C. et coll. (Coord.). La quête du sens: gérer nos organisations pour la santé des personnes, de nos sociétés et de la nature. Québec : Éditions de l'organisation, 1996. (Collection Manpower, p. 165-188)

JACQUES, E. Des systèmes sociaux comme défenses contre l'anxiété dépressive et l'anxiété de persécution. In: LÉVY, A. Psychologie sociale: textes fondamentaux anglais et américains. Paris: Dunod, 1978. Tome 2, p. 546-565.

KAPLAN, H. R., TAUSKY, C. The meaning of work among the hard-core unemployed. Pacific Sociological Review, v. 17, n. 2 , p. 185-198, 1974.

KETCHUM, L. D., TRIST, E. All teams are not created equal: how employee empowerment really works. Newbury Park : Sage, 1992

MORIN, E. M. L'efficacité organisationnelle et le sens du travail. In: PAUCHANT, T. C. et coll. (Coord.). La quête du sens: gérer nos organisations pour la santé des personnes, de nos sociétés et de la nature. Québec: Éditions de l'organisation, 1996. (Collection Manpower, p. 257-286).

MORIN, E. M. Le sens du travail pour des gestionnaires francophones. Revue Psychologie du Travail et des Organisations, v. 3, n. 2/3, p. 26-45, 1997.
MORSE, N. C., WEISS, R. C. The function and meaning of work and the job. American Sociological Review, v. 20, n. 2, p. 191-198, 1955.

MOW International Research Team. The meaning of working. New York : Academic Press, 1987.

PAUCHANT, T. C. La quête de l'excellence et le déni de la mort. In: PAUCHANT, T. C. et coll. (Coord.). La quête du sens: gérer nos organisations pour la santé des personnes, de nos sociétés et de la nature. Québec: Éditions de l'organisation, 1996. (Collection Manpower, p. 139-162).

SHEPHERDSON, K. V. The meaning of work and employment: psychological research and psychologists' values. Australian Psychologist, v. 19, n. 3, p. 311-320, 1984.

TAUSKY, C. Meaning of work among blue-collar men. Pacific Sociological Review, v. 12, n. 1, p. 49-55, 1969.

TRIST, E. Adapting to a changing world. Labour Gazette, v. 78, p. $14-20,1978$

VECCHIO, R. The function and meaning of work and the job: Morse and Weiss (1955) revisited. Academy of Management Journal, v. 23, n. 2, p. 361-367, 1990.

WARR, P. Work, unemployment and mental health. Oxford : Clarendon Press, 1987.

WEIL, S. La condition ouvrière. Paris : Éditions Gallimard, 1951.

NOTA

Este artigo é fruto de uma pesquisa financiada pela Direção de Pesquisas da HEC, Montreal. 